\title{
Analyses of Verb Tense and Voice of Research Article Abstracts in Engineering Journals
}

\author{
Mahjoobeh Abarghooeinezhad*, Shahla Simin \\ English Department, Najafabad Branch, Islamic Azad University, Najafabad, Iran \\ *E-mail address: mahjoobe_abarghooei@yahoo.com, shahlasimin@yahoo.com
}

\begin{abstract}
This paper seeks to analyze the research article abstracts among native English speakers and non-native (Iranian) speakers in the field of Electronic engineering. The analysis mainly focuses on the rhetorical structure, i.e. the constituent Moves/Sub-Moves. In addition, Verb choices and the voice and tense of the verbs in Move 2 and Move 4 respectively were examined. To this end, 25 published abstracts from each field (a total of 50 abstracts), all appearing in established, ISI journals, were selected. The model proposed by Santos (1996), composed of 5 moves along AntMover software was employed as a general guideline in order to identify Moves/SubMoves. The results compared and contrasted the dominant move patterns of each field, their unique Move/SubMoves, and the typical voice and tense of verbs employed in Move 4. It was also found that there were some variations between the abstracts written by native English speakers and nonnative speakers of English. It is hoped that with detailed analyses of abstracts, the results of this study may serve as a complement to the guidelines for novice writers to construct a proper research article abstract in electronic engineering.
\end{abstract}

Keywords: genre analysis; research article; abstracts; rhetorical moves; electronics

\section{INTRODUCTION}

The English language, which developed as a lingua franca in the late 19th and the early 20th centuries, "is now the dominant or official language of over 60 countries" (Alcaraz Ariza $\&$ Navarro, 2006, p.752). It is also the leading voice in almost all linguistic varieties of world communications through the Internet and the major foreign language in some countries including Iran. This wide usage of the English language, as the key means of world communication, has resulted in paying particular attention to writing in scientific English. Much credit is given to the research articles (RA) worldwide especially those published in universally-recognized journals as the type of discourse producing first-hand scientific ideas.

In the same way, technical writing is very significant in engineering domain as they become the main genre in reporting and communicating information among members in engineering community .Engineering authorities in Iran, like those in charge of other academic disciplines; do not to like to lag behind the worldwide competition of contributing to the development of engineering knowledge. They, therefore, attempt to measure the scientific productivity of their scholars and university professors by the number of articles they publish in prestigious international and national journals both in English and Persian, with ISI journals having the highest priority. On the other hand, publication is one of the channels that members of a research Community use to communicate their contribution to the 
field. "A scientific paper is not designed to be read. It is designed to be published", argues Day (1988, p. 5). Although this was said in jest, there is much truth to it. Similarly, Swales (1990) adds: "publication can be seen as documentary evidence that the writer qualifies for membership in the target discourse Community"(p.7). In either case, one might argue that the private effort of the researcher is to assume a public face, a face that has the power to represent the researcher. Thus, the oral presentation or the writing of an accurate, understandable paper is just as important as the research itself.

However, the lack of structural knowledge often makes English non-native engineers, adopt self teaching strategies in producing technical articles. They usually attempt to read the reports which have been written by other engineers in order to gain some ideas on how the reports are structured and what information to be included in the article, which leads to lack of innovations, creativity, and subjectivity on the part of the writers. Consequently, the rejection of the considerable number of Iranian articles in English by internationally reputable journals could possibly be due to their rhetorical deviations. "Every year only less than $7 \%$ of Iranian scientific publications find their way to international citations" (Mirsharifi, Aminian, \& Jafarian, 2008, p.7). The difficulty of non-native speakers of English involving in the production of knowledge due to their lack of information of the rhetorical features of native writers of English become crucial while, dealing with abstract of the articles. Abstract as an important part in the research article (RA) has gained significant attention from the academic community. Whereas, a well-written abstract can attract more readers and increases the chances of the accompanying RA being indexed and cited and offering a preliminary of the research, vague, unstructured and unsystematic one can lead to article rejection.

These days, abstracts have increasingly become a highly common and almost obligatory genre in the main research finding communications. Currently, most scholarly journals require an abstract accompany each original article. This is while, scholars for whom English is a second or foreign language like Iranian engineers, in order to promptly gain access to the work of their peers outside Iran as well as to efficiently communicate their research results to scholars in international areas are faced with the challenge of acquiring academic competencies in English. In contrast to abundant studies on compare/contrast the rhetorical features of native writers of English with those of writers of different other nations, not much study has been done considering the comparison of move structures and verb tense and voice choices of abstract section written by Iranian engineers especially in the field of electronic and their native English speaking counterparts. Unfortunately, most of our electronic engineers are unaware of the standard conventions of technical writings used by native English speakers, so conducting this study is essential in order to equip Iranian scholars, engineers in particular, with applicable pattern of writing scientific English and to develop awareness and mastery over the writing conventions of the technical articles by providing them with necessary information to be able to read/write RAs and to receive the latest updates in electronic, as well as to publish in English.

\section{BACKGROUND}

Following Swales' (1981) works on genre analysis, studies on different sections of research articles in various languages and fields abound. The rhetorical moves in abstract writing constantly undergo further examination and development. Santos' (1996) five-move model is an example. Noting the inadequacy of Swales' (1981) CARS model, he proposes that the organization of abstract writing could be characterized based on moves and each move has a clear function. Like Swales (1981) and Santos' (1996) framework of abstract analysis has also greatly influenced the works of researchers that came after him. One such 
work was by Pho (2008). Using Santos' model, he conducted a study on abstract writing in applied linguistics and educational technology. Although research into abstract writing have all pointed to the importance of a regular pattern in the organization of abstract writing, such convention in writing is somewhat unknown to L2 writers, particularly Iranian scholars due to the lack of studies done in Iranian context.

To date, regarding genre-based, few studies in the Iranian context have been conducted to clarify the nature of the medical and applied linguistic RAs (Falahati, 1994; Mohammadi khahan, 2006; Faghih \& Rahimpour, 2009; Bahrami \& Riazi, 2009 and Marefat \& Mohammadzadeh, 2013); however, from a genre-analytic perspective, no study has investigated the norms and conventions of engineering articles abstract, particularly electronic engineering. Therefore, this study for the first time seeks to compare and contrast the rhetorical moves in abstracts of Iranian and Native English speaking electronic engineers. This research will identify to what extend the rhetorical moves used in the abstracts of published articles by Iranian scholars approximate to their Native-English counterparts. Using Santos' (1996) five move pattern as the model of analysis, the data will reveal obligatory and optional moves from Iranian and native English scholars' point of view.

Move analysis, as articulated by Swales, represents academic research articles in terms of "hierarchically organized text made up of distinct sections; each section can be subdivided into moves, and each move can be broken into steps" (Kanoksilaptham, 2005, p.271). Based on what Swales $(1981,1990)$ revealed, move analysis is an influential means in order to explore a discourse internal organization. In other words, finding the regular move patterns and variations in the rhetorical move structures lead into characterizing the organization of different genres, which serves different communicative purposes. As mentioned earlier, Swales' (1981, 1990) has been widely used as a great model for researchers in analyzing move-pattern in various disciplines such as business writing (Bhatia, 1993; Hiranburana, 1996; Chakorn, 2002). Other studies which were also influenced by Swales' work are those by Graetz (1985) and Salvager-Meyer (1990). Graetz (1985) examines rhetorical moves in RA and found them to have the following pattern: Problem - Method - Results - Conclusion. On the other hand, Salvager-Meyer (1990) investigated the moves in the abstracts of research article and found that there were six moves. They are Statement - Purpose - Corpus/Method Results - Conclusion - Recommendation. It has also been found that besides the regular move pattern, variation in the rhetorical move structures is also observed in abstract writing. Huckin (2001), for example, found that the abstracts of medical fields often have the exclusion of stating the purpose as a move. Meanwhile, Kanokslapatham (2007) found that the occurrence of Move 3, Step 5: Announcing principal outcome in biochemistry (52 abstracts) occurs twice as frequently as in the microbiology (26 abstracts). As noted by Bhatia (1993), differences of style and rhetorical structures exist in the macro-organization of writing and they could be due to different genres serving different communicative purposes. Therefore, the result of above mentioned studies can be beneficial for L2 writers, who are unfamiliar with different genres conventions in writing. In the following examples, move analysis concerning with the abstracts, has been employed in order to identify the connection and variation in genres of different disciplines of the academic world. In a study of genre analysis at the move structure level, first a corpus of a target genre should be created. Next, researcher will select a model; this adoption of a move model should be based on an analysis of texts in the corpus. Moreover, inter-rater/coder reliability/agreement should be concerned if there is more than one coder. After that, moves and steps (submoves) are identified based on content and linguistic signals. The identified moves from the coders are then, counted. 
Finally, the statistical procedures for inter-coder agreement are calculated and the results of the move identification are presented.

\section{METHOD}

\subsection{The Corpus}

The corpus of this study consists of a total of 50 abstracts (25 IrIsI abstracts and $25 \mathrm{~N}-\mathrm{E}$ abstracts) Research Article abstracts in the field of electronic engineering which were randomly selected from published ISI journals by Iranian and native-English scholars between 2010 and 2014. The criteria for journal selection were representativeness, reputation, and online accessibility among the top ones with the highest impact factor in the discipline of Electronic engineering. For the Native-English category, articles were checked in terms of nationalities of their authors, therefore all writers were asked whether English is their first language or not through e-mail. To do a precise analysis, articles free from grammatical and textual errors were used. This was vital since the abstracts are supposed to be fed into the AntMover software for analysis.

\subsection{Instrumentation}

The study used two types of instrumentations:

1. AntMover software (developed by Laurence Anthony 2003)

AntMover is an automatic text structure analyzer program which is available on the Internet for free. Once a text file is opened in AntMover, it is imported into the program for analysis. The user can then choose up to four views of the file.

Each abstract from the corpus were fed into the AntMover for the identification of the Moves and Sub-Moves in the text.

2. Sants's(1996) five-move-pattern

This framework is designed for human coders. Human coders can use the Steps or SubMoves and the Moves depicted in this framework for the analysis of moves and steps in 'abstract' corpus; it is important that frequencies and percentages for each move be found, and the results be used as the data. Human coders can also use such linguistic features as words, structures, hedging devices, and citations for the identification of Moves and Steps. They can also closely read each text and use such organizational clues as headings and subheadings for identifying moves and steps.

\subsection{Analysis of the Verb Tense of Moves}

Having identified the moves/Sub-Moves the next phase, namely, the grammatical analysis, was conducted. In this phase, the tense (present/past) and the voice (active/passive) of the verbs characterizing Move4 were identified. Also, Move2 were analyzed in order to compare and contrast two groups in terms of their verb choices. 


\subsection{Inter-coder Agreement (Reliability)}

To avoid subjectivity, two coders were participating in the current study (the researcher herself and a Ph.D researcher). After receiving sufficient training in how to do the task, coders were asked to identify the Moves based on Santos (1996) model. Coding process was carried out independently. Inter -coder reliability was determined by comparing the coders output. As it was evident that satisfactory inter-coder agreement couldn't be easily achieved, the abstract's text file was submitted in Antmover software which was explained above. At last, Antmover identified Move was counted as an agreed Move were there disagreement occurred. An inter-rater reliability analysis using the Kappa statistic was performed to determine consistency among raters and the perfect agreement of 0.95 was estimated.

\section{RESULTS AND DISCUSSION}

\subsection{Move Identification}

To distinguish articles different Moves, all the 50 abstracts (25 Ir and $25 \mathrm{~N}-\mathrm{E}$ ) were analyzed thoroughly based on Santos' model (1996) to see what Move structures could be discovered in the abstract section of Iranian and Native-English RAs in the field of electronic engineering. In this subsection, all five Move and their Sub-Moves are presented with examples.

\subsubsection{Move1: Situating the Research}

Among 50 abstracts written by Iranian and Native-English authors, 12 occurrences in Iranian and 14 occurrences in Native-English groups were recognized. This initial Move is employed to attract the reader's attention by providing orientation to the reader in relation to where the writer is coming from while motivating him to examine the research to be reported (Santos, 1996). The obligatory element in Move 1 is SubMove 1, which 12 times were reported in both groups. This SubMove can take one of three predominating forms.

\subsubsection{Sub-Move1A: Stating Current Knowledge}

In this Sub-Move authors tend to identify the field by a stating that a given topic is of considerable Professional concern. The following sentences are samples of this Move found in Iranian abstracts.

(1) Low energy consumption and fault tolerance are often key objectives in the design of real-time embedded systems.

Also authors may offer readers something like generalization in this field.

(2) Feature extraction plays a central role in classification of hyperspectral data.

\subsubsection{Sub-Move1B: Citing Previous Research}

In this part authors attempt to give further credibility to the claim outlined in Sub-Move $1 \mathrm{~A}$ or Sub-Move 2 by relating what has been claimed to the person who has claimed it. Authors in this part provide reference to the state of previous research by mentioning the name of specific researchers. The following sentence is a sample of this Move found in N-E 
abstracts. Here it should be mentioned that no Iranian author has used this Sub-Move, while it was mentioned in N-E group once.

(3) Schalkwijk and Kailath (1966) developed a class of block codes for Gaussian channels with ideal feedback for which the probability of decoding error decreases as a second-order exponent in block length for rates below capacity.

\subsubsection{Sub-Move1C: Extending Previous Research}

In order to make clear that the current research is a part of an ongoing debate this SubMove is presented. This infrequent Sub-Move has only 2 examples in Ir group and none in NE group.

(4)This work extends previous research by studying the case where clutter is also present.

\subsubsection{Sub-Move 2: Stating a problem}

Problem Statements provide readers with some evaluation of the current state of knowledge as outlined in Sub-Move 1. These evaluations signify the degree of topic exploration already performed and the amount of knowledge currently available. In other words, problem Statements point out that previous research has not been thoroughly successful or complete. Sub-Moves of type 2 can take a variety of forms, but generally fall into two categories: (a) Statements that previous research is still developing; or (b) Statements that, despite long and intense discussion, there is still a continuing debate in current research. The following sentence is a sample of this Move found in Iranian abstracts.

(5) On the other hand, some of the existing coordination beamforming methods need computation of pseudo-inverse or generalized eigenvector of a matrix...

In general, these Sub-Moves indicate a fresh direction. In this section, authors by stating that a certain topic has remained relatively unexplored raise a need for further investigation. The second group of such Sub-Moves contains Statements to the effect that there is no full consensus concerning previous research.

\subsubsection{Move2: Presenting the Research}

The role of this Move is to make a kind of announcement that justifies the article either by describing the key features of the research in question, or by presenting its purpose.

Forty-eight of the 50 abstracts contain a Move 2, which means that this is an obligatory move in the abstract genre. Further, Move 2 in N-E and Ir groups opens 11 and 13 abstracts respectively. In N-E group all 11 instances directly follows Move 1, while in Ir group just 9 examples occurred directly. The second move can take one of two forms: a descriptive form or a purposive form.

\subsubsection{Sub-Move1A: Indicating Main Features}

There are 43 instances of descriptive Sub-Moves ( 21 Ir \& 22 N-E) which thus constitute almost all of the cases in the corpus.

(6)In this paper, we propose short length, high sensitive pressure, and temperature sensor based on hollow-core PCF.

(7) In this paper we propose a new practical demand response (DR) program. 
(8) In this study, for a single-relay regenerative system, the authors propose a spectrallyefficient incremental relaying scheme that eliminates redundant relay transmissions.

As it can be inferred from the data, there is a clearly predominating formula-like pattern employed by the Iranian and Native-English authors in the corpus. This pattern is used with limited chosen verbs and nouns as illustrated in Table 4.4 and 4.5 describing the inquiry genre in order to signal Move2.

Table 1. Iranian Choices in Move2/SubMove1A.

\begin{tabular}{|ll|}
\hline $\begin{array}{l}\text { Inquiry type } \\
\text { or genre }\end{array}$ & $\begin{array}{c}\text { Reporting } \\
\text { verb }\end{array}$ \\
\hline paper(13) & propose (11) \\
study (3) & present (6) \\
letter (1) & investigate(4) \\
design(1) & \\
study (1) & \\
use (1) & \\
\hline
\end{tabular}

Table 2. Native-English Choices in Move2/SubMove1A.

\begin{tabular}{|ll|}
\hline $\begin{array}{l}\text { Inquiry type } \\
\text { or genre }\end{array}$ & $\begin{array}{c}\text { Reporting } \\
\text { verb }\end{array}$ \\
\hline paper (9) & develop (5) \\
article (1) & present (3) \\
describe (2) & \\
propose (2) & \\
report (2) & \\
explore (1) & \\
explain (1) & \\
compare\&contrast(1) & \\
design (1) & \\
introduce (1) \\
provide (1) \\
\hline
\end{tabular}

\subsubsection{Sub-Move1B: Indicating Main Purpose}

Using this Sub-Move was only employed by Ir writers ( 7 instances) which used this purposive Sub-Move to carry the purposive nature via the verb phrase. Here is a sample of this Move found in Iranian abstracts.

(9) The main objective of the proposed control strategy of each distributed generation (DG) unit is to compensate the reactive power of its local loads and to share the reactive power of the nonlocal loads among itself and other DG units. 


\subsubsection{Sub-Move2: Hypothesis Raising}

Although descriptive and purposive Statements are the dominant means of presenting the research, there is still another exponent for introducing the work to be reported. Only one second move has been assigned to the category of Sub-Move 2-hypothesis raising. In hypothesis-raising Statements, authors outline their research hypotheses or questions. This sub-Move plays a supporting role in the presentation of research as it helps further detail the main features of the work in question. Here, in this sample the assumption has been expressed through modality.

(10) Consequently, link adaptation in V2V wireless networks may instead exploit the large-scale characteristics of the wireless channel.

\subsubsection{Move3: describing the Methodology}

When the abstract writer has completed the introduction of his/her research, $\mathrm{s} / \mathrm{he}$ then needs to offer some description of how the research was actually conducted. Thus, this move indicates the design of the study in terms of subjects, procedures, materials, Instruments, variables, according to the type of research.

Perhaps a more interesting finding has to do with the frequency with which this move occurs by itself and merges with other moves. Among N-E, in 13 abstracts, Move 3 appears as a separate move immediately after a descriptive Move 2. However, ( 7 instances) of Move 3 merges with Move 2, either partially or totally. Example (11) illustrates the realization of Move 2 and 3 occurring within the same sentence boundary (move embedding):

(11) In this paper, the acceleration of phase recovery in quantum-dot semiconductor optical amplifiers (QD-SOAs) is investigated by employing optical pumping (OP) scheme.

However, these hybrid moves differ in the amount of Information that Move 3 conveys. There are cases of only a brief mention of and cases where Move 3 occupies considerable textual space. It can thus be argued that authors utilize different strategies to indicate the research design.

\subsubsection{Move4: Summarizing the Results}

In this Move, the main findings of the research are summarized, and briefly indicated the way data were manipulated.

(12) The result comparison shows good agreement around the steady-state equilibrium.

(13) Analytical calculations and behavioral simulation results are provided.

In order to find out the differences between Ir and N-E tense and voice preferences in Move4 the two below tables have been provided.

Table 3. Tense and Voice in Move4of Ir Abstracts.

\begin{tabular}{cccc}
\hline Tense & \multicolumn{2}{c}{ Voice } & Total \\
\cline { 2 - 3 } Past simple & Passive & Active & $2(9 \%)$ \\
Present simple & 0 & $2(9 \%)$ & $19(91 \%)$ \\
Total & $9(43 \%)$ & $10(48 \%)$ & \\
\hline
\end{tabular}


Table 4. Tense and Voice in Move4 of N-E Abstracts.

\begin{tabular}{|c|c|c|c|}
\hline \multirow[t]{2}{*}{ Tense } & \multicolumn{2}{|c|}{ Voice } & \multirow[t]{2}{*}{ Total } \\
\hline & Passive & Active & \\
\hline Past simple & $1(5 \%)$ & 0 & $1(5 \%)$ \\
\hline Present simple & $8(42 \%)$ & $10(53 \%)$ & $18(95 \%)$ \\
\hline Total & $9(47 \%)$ & $10(53 \%)$ & \\
\hline
\end{tabular}

Surprisingly, no major differences have been observed between Ir and N-E groups tense and voice preferences in Move4. While in both categories of Ir and N-E there seems to be a strong preference for present tense (91\% and 95\%) which seems a risky task in Santos (1996) idea, indicates bold attempt to imply that the research reported has yield indisputable, established knowledge. On the other hand, in Santos (1996) applied linguistics authors preferred past tense in Move4, presumably because reference to one's own research results requires a narrow claim. The following Table shows Santos (1996) result.

Table 5. Tense and Voice in Move4.

\begin{tabular}{cccc}
\hline Tense & \multicolumn{2}{c}{ Voice } & Total \\
\cline { 2 - 3 } & Passive & Active & \\
Past simple & $46(20 \%)$ & $134(58 \%)$ & $180(78 \%)$ \\
Present simple & $8(3 \%)$ & $43(19 \%)$ & $52(22 \%)$ \\
Total & $54(23 \%)$ & $177(77 \%)$ & \\
\hline
\end{tabular}

Moreover, there were no significant differences between the verb voice choices among Ir and N-E articles.

\subsubsection{Move5: Discussing the Research}

After looking more closely at the problem than most other people, the researcher is therefore in a position to advance the significance of his/her work, i.e., to make Claims relative to the value or implication of the results obtained (Meurer, 1994). This Move covers both the evaluation of findings, and also the other type of Sub-Move.

\subsubsection{Sub-Move1: Drawing Conclusions}

This is the major Sub-Move of Move 5 which the conclusion is drawn. There are 8 and 9 instances of Sub-Movelin Ir and N-E groups respectively. Although, Santos (1996) believed that the arrival at this final move of the abstract is clearly signaled but unfortunately, in electronic RAs, Move4 and Move5 are deeply embedded in each other that distinguishing them were sometimes even impossible.

\subsubsection{Sub-Move2: Giving Recommendations}

Final part is meant to reveal answer to the question of 'So what?' This Sub-Move provides readers with future practice suggestions or investigations. 
In terms of text length, Iranian writers wrote a text length of 99-240 words. However, most Native-English writers (17 abstracts) were found to be within this text length. For the text length of 28-98 words, there was no abstract found from the Iranian writers. However, five abstracts were found to be from the Native-English writers. As for the text length of 240275 words, 3 Native-English writers' abstract were found as compared with the Iranian writers where no abstract was reported.

Table 6. The number of moves used of the Ir and N-E writers' abstracts based on the text length.

\begin{tabular}{|c|c|c|c|c|c|c|c|c|c|c|c|c|}
\hline \multirow{3}{*}{$\begin{array}{c}\text { Text } \\
\text { Length } \\
\text { (words) }\end{array}$} & \multicolumn{12}{|c|}{ Number of Rhetorical Moves Used by Ir and N-E Writers } \\
\hline & \multicolumn{2}{|c|}{1} & \multicolumn{2}{|c|}{2} & \multicolumn{2}{|c|}{3} & \multicolumn{2}{|c|}{4} & \multicolumn{2}{|c|}{5} & \multicolumn{2}{|c|}{$\begin{array}{c}\text { TOTAL } \\
\text { ABSTRACTS }\end{array}$} \\
\hline & Ir & En & Ir & En & Ir & En & Ir & En & Ir & En & Ir & En \\
\hline $28-98$ & 0 & 2 & 0 & 0 & 0 & 2 & 0 & 1 & 0 & 0 & 0 & 5 \\
\hline $99-160$ & 0 & 0 & 2 & 0 & 8 & 2 & 3 & 4 & 1 & 2 & 14 & 8 \\
\hline $160-240$ & 0 & 0 & 0 & 0 & 1 & 5 & 6 & 1 & 4 & 3 & 11 & 9 \\
\hline $240-275$ & 0 & 0 & 0 & 0 & 0 & 1 & 0 & 1 & 0 & 1 & 0 & 3 \\
\hline TOTAL & 0 & 2 & 2 & 0 & 9 & 10 & 9 & 7 & 5 & 6 & 25 & 25 \\
\hline
\end{tabular}

Key: Ir: Iranian Writers En: Native-English Writers

Within these varied text lengths, the majority of the abstracts were found to contain 3 to 4 moves. As found in Table 6 above, a total of 9 Iranian writers' and 10 Native-English writers' abstracts had 3 moves while 9 Iranian writers' and 7 Native-English writers' abstracts had 4 moves. Surprisingly, not so many authors used all the five moves. Only 5 Iranian writers' and 6 Native-English writers' abstracts were found to have all the 5 moves. Writing the abstracts with only one move was found in 2 Native-English writer's abstract. However, none of the Iranian writers wrote their abstracts with only one move. The sample of the one move abstract written by a novice writer is shown in Example 3.

(14) High-speed digital design and microwave design share a rich heritage of electrical engineering theory, yet, key differences separate these two fields and the people that work in them.

As can be seen above, the abstract which consists of one sentence has only one move which is Move1 (situating the research). On the other hand, not so many authors used all five Moves of a model suggested by Santos (1996). The abstract (see example 15) which was written by writer documents the five rhetorical Moves used in the abstracts.

Example 15

\begin{tabular}{|ccr|}
\hline & Sentence $\quad$ Pulsed Magnetic Field Assisted Technique & Moves \\
\hline S1 & $\begin{array}{c}\text { The commercial availability of long lengths of MgB2 conductor } \\
\text { with an increasingly attractive price-to-performance ratio encourages } \\
\text { its use in cryogen-free magnetic resonance imaging magnets. }\end{array}$ & Move1 \\
S2 & For such a magnet operating in persistent mode, connections \\
& between MgB2 wires must be completely superconducting to ensure & Move1 \\
& long-term magnetic field stability. & STR \\
\hline
\end{tabular}




\begin{tabular}{|lcr|}
\hline S3 & $\begin{array}{r}\text { A new electromagnetically assisted technique for joining MgB2 } \\
\text { conductors is proposed. }\end{array}$ & Move2 \\
S4 & An electrically conducting tube is electromagnetically formed & MTR \\
& around the wires to provide mechanical coupling. \\
S5 & Mg + 2B powder is placed inside this tube between the wire & DTM \\
& ends with exposed MgB2 cores. & Move3 \\
S6 & Pulsed magnetic field compression of the tube densifies the joint & \\
& powder, which is also redistributed into better contact with wire & Move3 \\
& cores, and forms the tube to the shape of the joined wires. & DTM \\
S7 & Cu powder has also been added into the Mg + 2B joint powder & Move3 \\
& to minimize the reactive diffusion between Mg and Cu components. & DTM \\
S8 & Finite element modeling of the deformation process will be & \\
& presented, along with critical current measurements performed on & Move4 \\
& a joint and on the individual wire for comparison. & STF \\
S9 & The applicability of this method for joining wires in reacted & Move5 \\
& and unreacted form for magnet applications will be discussed. & DTR \\
& & \\
\hline
\end{tabular}

As above mentioned, there are twenty-one and twenty-two instances of Move2 descriptive Sub-Moves in Ir and N-E articles respectively, which thus constitute almost all of the cases in the corpus. These numerous cases, made researcher interested in studying them in particular. As it can be inferred from Table1 and Table 2, there is clearly a predominating formula-like pattern employed by Iranian authors in the corpus to signal their Move2 compared with their Native-English counterparts who didn't seem to follow a specific model. As illustrated in Table4.4, there is a clear preference in Ir articles to mention their inquiry type or genre $(70 \%)$ while, only less than half of the N-E ones expressed them.

Moreover, this pattern being shown in Table1 seems to contain a restriction concerning the verb selections among Iranian authors. Three main verbs (propose, present, investigate) mentioned in Ir abstract compared with a list of various verbs in N-E articles revealed Iranian insufficient vocabulary knowledge.

\section{CONCLUSION AND IMPLICATIONS}

As discussed in detail, the Move analysis of RA abstracts revealed the existence of both similarities and variations in the rhetorical structure as well as linguistic features between the abstracts of the Native and Non-Native (Iranian) English abstracts. As for the linguistic analysis, the results indicated the dominance of present tense verbs with active and passive voices almost equally both groups.

Beside Move deployment, other rhetorical aspects of writing electronic engineering RAs can tremendously influence comprehensibility of the discourse, thus the illocutionary force of the ideas. On the other hand, the quality of paragraph development, the degree of fluency, and the amount of errors in form in this study were found to further affect Move/SubMove identification. As Move/Sub-move recognition deals with understanding the way information has been organized, these last three factors can also affect the degree of overall comprehensibility of an article on the part of the reader. It is noteworthy to point out that, as experienced by the researcher and the raters of the present study, during Move identification in Iranian Electronic engineering RAs, the existence of proper metadiscourse markers was even able to effectively compensate for the flaws in the rhetorical quality of an article 
regarding the three factors mentioned above. The reverse did not turn out to be true. This means that even robust paragraph development, high degree of fluency, and absence of grammatical errors together could not completely compensate for the damage to comprehensibility caused by lack of metadiscourse markers.

Although, the lack of metadiscoursre markers caused unintelligibility and ambiguity in interpreting the intended information in Iranian articles, insufficient skill in paragraph developing can be another crucial factor. It was quite apparent that a considerable number of the writers of Iranian articles were not aware of the rhetorical constraints of paragraph development in English language. This problem might have been caused by the fact that, in Iran, no paragraph development skills are offered as part of the curriculum of either primary or secondary education. This lack of knowledge has caused Iranian engineering writers to follow a type of almost unorganized manner of writing styles as supported by Katchens (1982) finding. Therefore, it is usually difficult for Iranian learners of English to understand and apply regulations of English paragraph development thus tend to transform the same unrestricted writing style into their English performances.

From the theoretical point of view, analyzing Abstracts from the perspective of genre make extensive contribution to the knowledge about Move patterns in the Iranian context. This analysis strived to identify engineering generic components and regularities of form and content with the purpose of providing language learners with tentative model of communication in this genre. This study partially satisfies its main goal, and it just raises other questions and hypotheses on the issue in the reader's mind in addition to the addressed research questions.

The present research analyzed Native and Non-Native (Iranian) English abstracts. Future research could take language into account as well and as dual contrastive analysis investigate the effects of both discipline and language in the generic structure of the abstract. In addition, this study was conducted on 50 abstracts. Future research should be conducted on a bigger corpus including more disciplines. Also, while the current study included only written discourse analysis, future studies can take one step further by carrying out interviews with the authors so as to explore the socio-cultural factors more comprehensively.

\section{References}

[1] Anthony, L. (2003). Ant Mover. Retrieved from http://www.antlab.sci.waseda.ac.jp/software.html

[2] Alcaraz Ariza, M. \& Navarro, F. (2006). Medicine: Use of English. In Encyclopedia of language and Linguistics. Retrieved from http://www.sciencedirect.com/science/referenceworks/9780080448541

[3] Bahrami, A. \& Riazi, A. (2009, October). Iranian scholars and scientific publications in English: Attitudes, problems and strategies. Teaching English Language and Literature Society of Iran, 3(11), 33-59.

[4] Bhatia, V. (1993). Analyzing genre: Language use in professional settings. New York: Longman.

[5] Chakorn, O. (2002). Promotional Writing in the Thai Business Context: A Cross-Cultural Analysis of Sales Promotional Letters. NIDA Language and Communication Journal, 7 , $1-26$. 
[6] Day, R. (1988). How to Write and Publish a Sientific Paper (3rd ed.). Cambridge: Cambridge University Press.

[7] Faghih, E., \& Rahimpour, S. (2009). Contrastive rhetoric of English and Persian written text: Metadiscourse in applied linguistic research articles. Rice Working Papers in Linguistic, 1, 92-107.

[8] Falahati, R. (1994). The use of hedging across different disciplines and rhetorical sections of research articles. Paper presented at the $22^{\text {nd }}$, International Conference on East Asian Linguistics (ICEAL2), Vancouver, Canada. Retrieved from http://www.sfu.ca/content/dam/sfu/linguistics/Gradlings/NWLC_Proceedings/falahati99112.pdf

[9] Graetz, N. (1985). Teaching EFL students to extract structural information from abstracts. In J. M. Ulign, \& A. K. Pugh (Eds.), Reading for professional purposes: Methods and materials in teaching languages (pp. 123-135). Leuven: Acco.

[10]GRAETZ, N. (1985): «Teaching EFL students to extract structural information from abstracts» en

[11]Ulign, J.M. y Pugh, A.K. (eds.), Reading for Professional Purposes: Methods and Materials in Teaching Languages. Leuven: Acco, 123-135.

[12]Hiranbuna, K. (1996). Cross-Cultural Startegies and the Use of English in International Business Correspondence (Unpublished PhD thesis). Flinders University of South Australia, Australia.

[13]Huckin, T. N. (2001). Abstracting from abstracts. In M. Hewings (Ed.), Academic writing in context. Birmingham: University of Birmingham Press.

[14]Kanoksilapatham, B. (2005). Rhetorical structure of biochemistry research articles. English for Specific Purposes, 24(3), 269-292.

[15]Kanoksilapatham, B. (2007). Rhetorical Organizations of Research Article Introductions in Biochemistry and Microbiology.ESPMalaysia. A Journal on English for Specific Purposes. 13 (2), 21-37.

[16]Katchen, J, E. (1982). A structural comparison of American English and Farsi expository writing. Papers in linguistics, 15(3), 165-180.

[17] Marefat, H. \& Mohammadzadeh, S. (2013). Genre analysis of literature research article abstracts: A cross-linguistic, cross-cultural study. Applied Research on English Language, 2(2), 37-50.

[18]Mirsharifi, R., Aminian, A., \& Jafarian, A. (2008). The top 50 Iranian surgical articles.

[19] Shiraz E-Medical Journal, 9 (2), 97-104. Retrieved from http://semj.sums.ac.ir/vol9/apr2008/86033.pdf

[20]Meurer, J. L. (1994). Resenha critica: V SIMPLA—Jogos de Linguagem. Boletim Associafao de Linguistica Aplicada do Brasil 3, 22-25.

[21] Mohammadi Khahan, F. (2006). A contrastive analysis of the frequency and types of hedges and boosters used in Results and Discussion sections of medical and applied linguistics research articles written by PNS and ENS researchers (Unpublished MA thesis). University of Teacher Education, Tehran, Iran. 
[22]Pho, P. D. (2008). Research article abstracts in applied linguistics and educational technology: a study of linguistic realizations of rhetorical structure and authorial stance. Discourse Studies 10(2), 231-250.

[23] Santos, M. B. D. (1996). The textual organization of research paper abstracts in applied linguistics. Text, 16, 481-499.

[24] Salager-Meyer, F. (1990). Discoursal flaws in medical English abstracts: A genre analysis per research and text-type. Text, 10(4), 365-384.

[25] Swales, J. M. (1981). Aspects of article introductions in: ESP Research Reports, Aston University, Birmingham, U. K.

[26] Swales, J. M. (1990). Genre analysis. English in academic and research settings. Cambridge: Cambridge University Press.

\section{Appendix A}

Santos' (1996) Framework for Abstract Analysis

\begin{tabular}{ccc}
\hline Moves & Function/Description & Question asked \\
\hline
\end{tabular}

Move 1: Situating the research Setting the scene for the current Research(topic generalization) known about the field

$<$ STR $>$

Move 2: Presenting the research $<$ PTR $>$
What is the study about?
What has been /topic of research?
Stating the purpose of the study, Research questions and/or hypotheses

Describing the materials, subjects, ariables, procedures

Reporting the main findings of the Study

Interpreting the results/findings And/or giving recommendations Implications/applications of study
Move 4: Summarizing the
findings $<$ STF $>$

Move 5: Discussing the research

$<$ DTR $>$ 